\title{
P01.23. Effects of unilateral facet fixation and facetectomy on muscle spindle responsiveness during simulated spinal manipulation
}

\author{
W Reed", J Pickar \\ From International Research Congress on Integrative Medicine and Health 2012 \\ Portland, Oregon, USA. 15-18 May 2012
}

\section{Purpose}

There is mounting evidence that identification of spinal joint hypo- and hypermobility along with correspondingly tailored manual therapy treatment approaches for these clinical subgroups can lead to more successful therapeutic outcomes. Subjects with spinal joint hypomobility had higher therapeutic success rates with spinal manipulation than subjects with spinal joint hypermobility (Fritz et al. Arch Phys Med Rehab 2005;86:1745-52). We were interested in whether changes in segmental mobility affect proprioceptive signaling from paraspinal muscles during spinal manipulation having thrust durations similar to those delivered clinically $(75,100,150$, 250ms).

\section{Methods}

In the same anesthetized cat preparation, the $\mathrm{L}_{5-6}$ facet joints remained intact bilaterally, were screwed together unilaterally with a $10 \mathrm{~mm}$ dental screw (fixation) or were completely removed unilaterally (facetectomy). All fixated/facetectomized preparations had at least a $4 \%$ change (increase/decrease) respectively in joint stiffness compared to the intact condition. Single unit activity from longissimus or multifidus muscle spindles was recorded from the $\mathrm{L}_{6}$ dorsal root. The $\mathrm{L}_{6}$ vertebra was manipulated in the posterior-to-anterior direction using a computer-controlled feedback motor coupled to the $\mathrm{L}_{6}$ spinous process through a pair of forceps.

\section{Results}

Compared to baseline discharge, average mean instantaneous discharge frequency $(\Delta \mathrm{MIF})$ changed as follows [mean (SD) in impulses per second]:
Table 1

\begin{tabular}{|c|c|c|c|c|}
\hline $\begin{array}{l}\text { MANIPULATIVE THRUST } \\
\text { DURATION: }\end{array}$ & $\underline{75 \mathrm{~ms}}$ & $100 \mathrm{~ms}$ & $150 \mathrm{~ms}$ & $250 \mathrm{~ms}$ \\
\hline Fixation $(n=18)$ : & $\begin{array}{l}102.8 \\
(65.7)\end{array}$ & $\begin{array}{l}85.5 \\
(51.6)\end{array}$ & $\begin{array}{l}61.0 \\
(36.1)\end{array}$ & $\begin{array}{l}46.6 \\
(25.7)\end{array}$ \\
\hline Intact ( $n=18)$ : & $\begin{array}{l}116.9 \\
(60.4)\end{array}$ & $\begin{array}{l}99.3 \\
(55.1)\end{array}$ & $\begin{array}{l}73.2 \\
(34.5)\end{array}$ & $\begin{array}{l}51.6 \\
(22.6)\end{array}$ \\
\hline Facetectomy $(n=8)$ : & $\begin{array}{l}114.3 \\
(54.5)\end{array}$ & $\begin{array}{l}101.2 \\
(68)\end{array}$ & $\begin{array}{l}70.7 \\
(36.1)\end{array}$ & $\begin{array}{l}55.6 \\
(27.1)\end{array}$ \\
\hline
\end{tabular}

At each duration, compared with the intact condition $\Delta$ MIF during the manipulative thrust decreased with facet joint fixation but remained similar with facetectomy. In addition, the relationship between $\triangle$ MIF and changes in joint stiffness was not linear.

\section{Conclusion}

The data suggest that segmental hypomobility but not segmental hypermobility alters the responsiveness of paraspinal muscle spindles during clinically relevant high velocity spinal manipulation. We speculate that difference in manipulation-evoked sensory input may relate to differences in spinal manipulation's effects in subjects with hypomobility versus hypermobility.

Published: 12 June 2012

doi:10.1186/1472-6882-12-S1-P23

Cite this article as: Reed and Pickar: P01.23. Effects of unilateral facet fixation and facetectomy on muscle spindle responsiveness during simulated spinal manipulation. BMC Complementary and Alternative Medicine 2012 12(Suppl 1):P23.

Palmer College of Chiropractic, Davenport, USA 